\title{
Analysis of Surface Hardness of Artificially Aged Resin Composites
}

\author{
Denise Cremonezzi Tornavo ${ }^{\mathrm{a} *}$, Sandra Sato ${ }^{\mathrm{a}}$, Leandro Jardel Silva ${ }^{\mathrm{a}}$, \\ José Augusto Marcondes Agnelli ${ }^{\mathrm{b}}$, Andréa Cândido dos Reis ${ }^{\mathrm{a}}$ \\ ${ }^{a}$ Department of Dental Materials and Prosthesis, School of Dentistry of Ribeirão Preto, \\ University of São Paulo - USP, Ribeirão Preto - SP, Brazil \\ ${ }^{b}$ Department of Materials Engineering, Federal University of São Carlos - UFSCar,
}

São Carlos, SP, Brazil

Received: January 20, 2011; Revised: October 18, 2011

\begin{abstract}
This study evaluated the effect of artificially accelerated aging (AAA) on the surface hardness of eight composite resins: Filtek Z250, Filtek Supreme, 4 Seasons, Herculite, P60, Tetric Ceram, Charisma, and Filtek Z100. Sixteen specimens were made from the test piece of each material, using an $8.0 \times 2.0 \mathrm{~mm}$ teflon matrix. After 24 hours, eight specimens from each material were submitted to three surface hardness readings using a Shimadzu Microhardness Tester for 5 seconds at a load of $50 \mathrm{gf}$. The other eight specimens remained in the artificially accelerated aging machine for 382 hours and were submitted to the same surface hardness analysis. The means of each test specimen were submitted to the Kolmogorov-Smirnov test $(\mathrm{p}>0.05)$, ANOVA and Tukey test $(\mathrm{p}<0.05)$. With regard to hardness $(\mathrm{F}=86.74, \mathrm{p}<0.0001)$ the analysis showed significant differences among the resin composite brands. But aging did not influence the hardness of any of the resin composites $(F=0.39, p=0.53)$. In this study, there was interaction between the resin composite brand and the aging factors $(\mathrm{F}=4.51$, $\mathrm{p}<0.0002$ ). It was concluded that notwithstanding the type of resin, AAA did not influence surface hardness. However, with regard to hardness there was a significant difference among the resin brands.
\end{abstract}

Keywords: composite resin, surface hardness, accelerated artificial aging

\section{Introduction}

Much research has been carried out to analyze the mechanical and esthetic properties of resin composites ${ }^{21}$ in order to find an ideal material to replace lost dental structures. These studies have led to considerable scientific, industrial and technological development over the last few years, demonstrating their increasing use in anterior and posterior teeth 6 .

Currently, resin composites occupy an outstanding place among restorative materials in Dentistry ${ }^{26}$. Resin composites were introduced in the 1960s for the restoration of anterior teeth $^{3}$, showing good durability. However, in posterior teeth, due to the great masticatory forces they are subjected to, an evaluation is needed.

Hardness determines the degree of deformation of a material and is generally accepted as an important property and a valuable parameter for comparison with the tooth structure $^{8}$. To assess hardness, tests based on the materials' capacity to resist the penetration of a tip are performed, and the Knoop hardness test is the most commonly indicated method for resin composites ${ }^{6}$.

A Broad knowledge of the physical properties of dental materials is important to understand the mechanical behavior under clinical conditions ${ }^{24}$ and their satisfactory performance is determined by its resistance to degradation in the oral medium ${ }^{13}$.

*e-mail: dctornavoi@hotmail.com
There are some drawbacks to evaluate materials in vivo due to the variables, as for instance differences in the diet, ph of the oral cavity, microbiota, the operators' skill, restoration methods that are difficult to standardize, differences in the required treatment and time factor ${ }^{20}$. As for time, the major problem stems from the rapid industrial development and the insecurity of professionals due to the large number of commercial brands available in the market ${ }^{12}$.

In order to predict the relative durability of the material ${ }^{4}$, laboratory methods are used, such as the Comexin system ${ }^{12}$, which simulates the conditions of the oral environment to combine an analysis of the behavior of materials not only under occlusal forces, but also considering the complexity of the oral environment, which involves another aspect of degradation, in a faster and more standardized manner ${ }^{16}$. This system operates through pre-fixed cycles of ultraviolet light $\mathrm{B}$ with radiation between $280 / 320 \mathrm{~nm}$, temperature variations between $0^{\circ}$ and $300^{\circ}$ indicated by a precision and humidity thermometer, by condensation with distilled water saturated with oxygen, simulating destructive forces of nature ${ }^{12}$

Some authors ${ }^{14,19}$ have reported that an increase in the load percentage results in less water absorption and greater strength of the material. By promoting the degradation of resin composites, accelerated artificial aging may reduce the mechanical properties by degrading the matrix and altering the structural distribution of these particles ${ }^{9}$. 
Thus, factors such as the type, number, size and distribution of filler load influence the mechanical properties of resin composites, such as surface hardness ${ }^{29}$. Therefore, this study proposes to demonstrate the effect of the accelerated artificial aging method (AAA) on the surface hardness of 8 types of resin composites with different compositions, available in the dental market.

\section{Materials and Methods}

\subsection{Materials}

For this study, 8 light-polymerized resins were used, specified in Table 1 .

\subsection{Accessories and equipment}

The accessories used were: Teflon matrixes (composed of three components: the base has a plunger with an outer diameter of $8 \mathrm{~mm}$. The spacer, $2 \mathrm{~mm}$ in height and $8 \mathrm{~mm}$ in diameter and a component that has an inner hole of $8 \mathrm{~mm}$ diameter to insert the plunger into the base. This matrix was used to prepare the resin samples (measuring $8 \times 2 \mathrm{~mm}$ ), Ward type manual condenser (S.S. White, Rio de Janeiro, RJ, Brazil), dentin curette (S.S. White, Rio de Janeiro, RJ, Brazil), glass slide, Ultralux EL photopolymerizer from Dabi-Atlante (Ribeirão Preto, SP, Brazil), silicone Rhodiastic 303 (Paulínia, São Paulo, SP, Brazil), polishing superfine dental kit Sof-Lex Pop-On, (3M Dental Products,
St. Paul, MN, EUA). The Teflon matrix used was perfectly smooth inside, thereby meeting the necessary requirements to obtain regular test specimens that were easily removed from the matrixes.

The tests were performed in an Accelerated Artificial Aging Machine for non-metal materials (C-UV) and the Shimadzu HMV-2000 microhardness tester (Kyoto, Japan) of the School of Dentistry of Ribeirão Preto.

\subsection{Method}

The test specimens measuring $8 \mathrm{~mm}$ in diameter and $2 \mathrm{~mm}$ in height were obtained with a Teflon matrix. The material was inserted into the matrix in two increments and when the resin settled in the matrix, it was light polymerized with an Ultralux Electronic device (Dabi Atlante) using the time interval indicated by the manufacturer. For each resin, 16 test specimens were obtained and then divided into 2 groups of 8 , in which one group was submitted to surface hardness analysis without undergoing AAA, and the other was submitted to the same analysis after AAA.

\subsubsection{Accelerated artificial aging}

After finishing and polishing with the kit Sof-Lex PopOn $3 \mathrm{M}$ in a sequence of abrasiveness with intermittent movements, interspersed with the wetting of the test specimens to prevent overheating and surface modification, these were stored in separate plastic receptacles moistened with distilled water to maintain a relative humidity of $100 \%$

Table 1. Description of the resin composites used.

\begin{tabular}{|c|c|c|c|}
\hline Resin composite & Classification & Organic matrix & Inorganic content \\
\hline $\begin{array}{l}\text { Z } 250 \\
\text { (3M, Dental Products Co., } \\
\text { St. Paul, MN, USA) }\end{array}$ & Microhybrid & $\begin{array}{l}\text { Bis-GMA, UDMA, } \\
\text { Bis-EMA }\end{array}$ & $\begin{array}{l}\text { Zirconium/Silica } 60 \% \text { by volume } \\
(0.01 \text { to } 3.5 \mu \mathrm{m})\end{array}$ \\
\hline $\begin{array}{l}\text { SUPREME } \\
\text { (3M, Dental Products Co., } \\
\text { St. Paul, MN, USA) }\end{array}$ & Nanoparticle & Bis-GMA, UDMA & $\begin{array}{l}\text { Nano-silica }(20 \mathrm{~nm})+\text { zirconium/silica } \\
\text { nanoagglomerates }(5-20 \mathrm{~nm}) 59.5 \% \text { by vol }\end{array}$ \\
\hline $\begin{array}{c}\text { 4 SEASONS } \\
\text { (Ivoclar/VivadentAG Schaan, } \\
\text { Liechtenstein) }\end{array}$ & $\begin{array}{l}\text { Microhybrid with } \\
\text { nanoparticles }\end{array}$ & $\begin{array}{l}\text { BIS-GMA, TEGMA, } \\
\text { UDMA }\end{array}$ & $\begin{array}{l}76 \% \text { of Ytterbium trifluoride barium glass } \\
\text { loading, Ba-Al-fluorosilicate and dispersed silica } \\
0,04 \text { to } 3 \mu \mathrm{m}\end{array}$ \\
\hline $\begin{array}{c}\text { HERCULITE } \\
\text { (Kerr, Romulus, MI, USA) }\end{array}$ & Microhybrid & Bis-GMA, TEGDMA & $\begin{array}{l}\text { Aluminum borosilicate glass and colloidal silica. } \\
\text { Load }-79 \% \text { by weight or } 59 \% \text { by volume with } \\
\text { mean size of } 0.6 \mu \mathrm{m}\end{array}$ \\
\hline $\begin{array}{c}\text { P } 60 \\
\text { (3M, Dental Products Co., } \\
\text { St. Paul, MN, USA) }\end{array}$ & Condensable & $\begin{array}{l}\text { Bis-GMA, UDMA, } \\
\text { BIS-EMA }\end{array}$ & $\begin{array}{l}\text { Zirconium/silica } 61 \% \text { by volume } \\
(0.01 \text { to } 3.5 \mu \mathrm{m})\end{array}$ \\
\hline $\begin{array}{c}\text { TETRIC CERAM } \\
\text { (Ivoclar/VivadentAG Schaan, } \\
\text { Liechtenstein) }\end{array}$ & Microhybrid & $\begin{array}{l}\text { Bis-GMA, TEGDMA, } \\
\text { UDMA }\end{array}$ & $\begin{array}{l}60 \% \text { by volume } \\
70 \% \text { by weight } \\
\text { - Barium glass } \\
\text { - Ytterbium trifluoride } \\
\text { - mixed oxides } \\
\text { - aluminum and barium fluorosilicate glass } 0.7 \mu \mathrm{m}\end{array}$ \\
\hline $\begin{array}{l}\text { Z } 100 \\
\text { (3M, Dental Products Co., } \\
\text { St. Paul, MN, USA) }\end{array}$ & Microhybrid & Bis-GMA, TEGDMA & $\begin{array}{l}\text { Zirconium/ } 100 \% \text { silica } \\
\text { - } 71 \% \text { by volume }(0.6 \mu \mathrm{m})\end{array}$ \\
\hline $\begin{array}{c}\text { CHARISMA } \\
\text { (Heraeus Kulzer, } \\
\text { Dormagen, Germany) }\end{array}$ & Microhybrid & Bis-GMA, TEGDMA & $\begin{array}{l}\text { Barium glass, fluoride aluminum } \\
(0.02-2 \mu \mathrm{m}), \text { highly dispersed silica dioxide } \\
(0.02-0.07 \mu \mathrm{m}) 60 \% \text { by vol }\end{array}$ \\
\hline
\end{tabular}


and kept in the absence of light until they were inserted into the C-UV accelerated aging system ${ }^{12}$.

The artificial aging system for non metallic materials is a laboratory equipment that simulates the environmental destructive capacity by physical and chemical means, in order to predict the relative durability of the materials exposed to degradation in the oral environment ${ }^{23,20}$.

Saliva is simulated by the condition of $100 \%$ humidity and by a condensation process and by the effect of light using UV light sources with a concentrated radiation ranging between 280-320 $\mathrm{nm}^{12}$.

To perform accelerated artificial aging (AAA), the test specimens were fixed with silicone (Rhodiastic 303) specific for this purpose, in an aging machine device, at a distance of $50 \mathrm{~mm}$ from the light source.

This machine has a control system that enables to control the programs daily interspersing separate cycles of condensation and UV-B irradiation, which are repeated automatically ${ }^{23,12}$. The program was set for 4 hours of exposure to UV-B at $50{ }^{\circ} \mathrm{C}$ and 4 hours of condensation at $50{ }^{\circ} \mathrm{C}$ and maximum aging time of 382 hours.

Condensation is performed by exposing the surfaces of the composites to water vapor saturated with high-purity oxygen. A chronometer indicates the total operation time of exposure to light, and a thermometer with a precision of $-1{ }^{\circ} \mathrm{C}$ operating at a temperature between 0 and $300{ }^{\circ} \mathrm{C}$. In a few days the machine produces degradations that would otherwise occur in months or years ${ }^{20}$.

The C-UV accelerated aging system for non metallic materials was used following the ASTM-G-53 standards ${ }^{1}$.

\subsubsection{Hardness test}

The test to assess the surface hardness was performed in the Laboratory of Laser Welding and Corrosion Analysis of the Department of Prosthesis and Dental Materials at the School of Dentistry of Ribeirão Preto (FORP-USP), using a Shimadzu microhardness tester, model HMV-2000.

The measurements were performed with a Knoop type diamond penetrator under a load of $50 \mathrm{gf}$ for 5 seconds, totaling 3 random equidistant measurements on each test specimen, covering different surface areas. The indentations were measured by two markings on the vertices of the rhombus in a $40 \times$ magnified image, determining the largest diagonal length and consequently, the results of the Knoop hardness by means of an automatic calculation made by the software:

$\mathrm{KHN}=\mathrm{c} \cdot \mathrm{C} / \mathrm{d}^{2}$

where:

- $\mathrm{KHN}=$ Knoop hardness value;

- $\mathrm{C}($ constant $)=14.230$;

- $\mathrm{C}=50 \mathrm{gf}$; and

- $\mathrm{D}=$ length of the largest indentation diagonal

The surface hardness values of each test specimen obtained before and after performing the accelerated artificial aging procedure were submitted to statistical analysis using the normality test (Kolmogorov-Smirnov $\mathrm{p}>0.05=$ normality), the parametric test (ANOVA) and the test for multiple comparisons (TUKEY- $\mathrm{p}<0.05=$ level of significance). The software used for statistical analysis was NCSS 2007 (NCSS, Kaysville, USA).
Table 2. Arithmetic mean of the 3 readings of each test specimen: NA - non-aged; A- aged.

\begin{tabular}{lc}
\hline Group & Mean $($ HK) \\
\hline Charisma NA & 55.10833 \\
Charisma A & 58.3875 \\
Tetric Ceram NA & 63.96667 \\
Tetric Ceram A & 60.175 \\
Seasons NA & 62.5875 \\
Seasons A & 62.27917 \\
Herculite NA & 72.80417 \\
Herculite A & 69.17083 \\
Supreme NA & 78.4125 \\
Supreme A & 72.42416 \\
Z250 NA & 77.39167 \\
Z250 A & 88.51667 \\
P60 NA & 77.9375 \\
P60 A & 88.9375 \\
Z100 NA & 107.3375 \\
Z100 A & 101.5208 \\
\hline
\end{tabular}

\section{Results}

The study sample consisted of $\mathrm{N}=8$ repetitions ( 8 resins $\times 2$ aging conditions $\times 8$ test specimens $=128$ data $)$. An arithmetic mean was made of the 3 readings of each test specimen, using only the averages calculated for each one of the 128 test specimens for the statistical analysis (Table 2).

In the figure that shows the statistical analysis results, the non-aged composite resins are represented by letters (A, B, C, D, E and F) and the aged ones by numbers (1, 2, 3, 4 and 5) (Figure 1). The statistical difference for surface hardness is shown in the figure when commercial brands have different letters (non-aged resins) and numbers (aged resins).

Analyzing a composite before and after artificial accelerated aging, it was observed that this process did not influence the surface hardness of any of the brands under study $(\mathrm{F}=0.39, \mathrm{p}=0.53)$. However, different commercial brands showed different surface hardness $(\mathrm{F}=86.74$, $\mathrm{p}<0.0001)$, with an interaction between the brand and aging of the composite resin $(\mathrm{F}=4.51, \mathrm{p}<0.0002)$. The Z100 resin, before and after AAA, exhibited surface hardness that was statistically superior to all others.

\section{Discussion}

Among the known mechanical tests to evaluate and compare the composite resins, the most widely used is microhardness ${ }^{18}$, largely studied and acknowledged as a highly reliable method and able to suggest the pre-selection of these materials ${ }^{28}$.

Both physical and chemical processes have an effect on the degradation of the composites in the oral cavity, compromising the material and reducing the longevity of the restoration and its mechanical properties ${ }^{15}$. Mayworm et al. ${ }^{17}$, reported that the microhardness of the composites decreases after storage in artificial saliva. Another attribute that may 


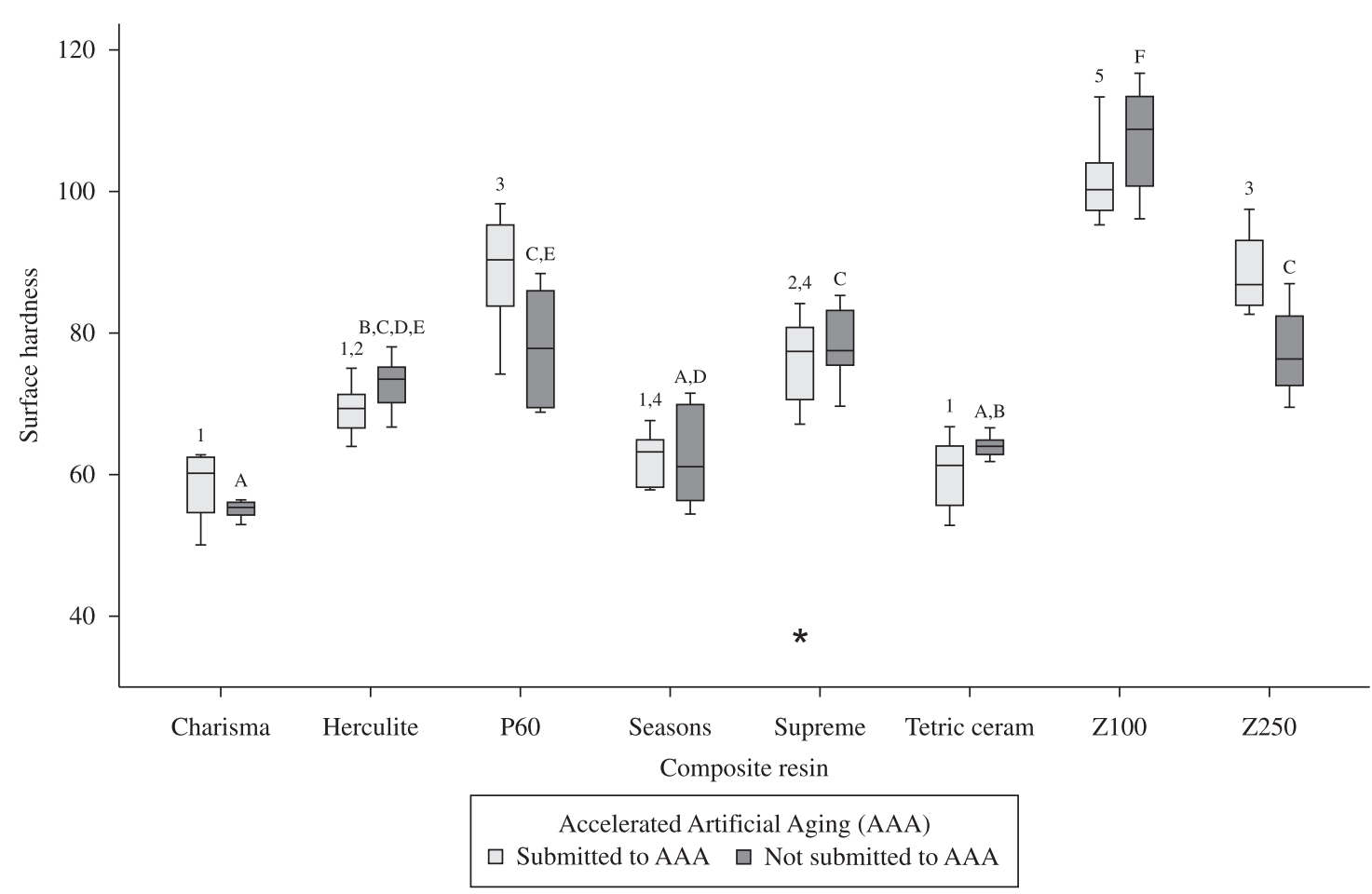

Figure 1. Surface hardness before and after accelerated artificial aging: different numbers indicate significant hardness differences only between the aged resins (Tukey test $-\mathrm{p}<0.05$ ), while different letters indicate differences between the non-aged resin composites (Tukey test $-\mathrm{p}<0.05)$

be modified over time is the degree of polymer conversion of the resins, which is closely related to microhardness ${ }^{10}$.

To evaluate the long term behavior of materials in a short period of time and in a standardized way, equipment that promotes accelerated artificial aging may be used, which simulate the existing conditions in the oral environment ${ }^{4}$.

The manufacturers and the literature classify the composed resins according to the number, shape and size of the filler load. Regarding size, the resins are divided into: macroparticles or conventional ( 8 a $10 \mu \mathrm{m})$, microparticles ( 0.04 to $0.4 \mu \mathrm{m})$, hybrids $(0.4$ to $1 \mu \mathrm{m})$ and nanoparticles (5 to 70 nanometers) $)^{5}$.

Continuous changes are performed to improve the mechanical and aesthetic properties in resin compositions, as for instance reducing size and increasing the amount of inorganic particles ${ }^{22}$, in addition to changes in their form and distribution, hence reducing the wear and degradation associated with the polymer matrix ${ }^{2}$.

Although this technology is applied to improve the mechanical properties and manipulation characteristics of the materials, little is known about the effect of time on these composites, and the changes caused in the mechanical properties. Thus, this study evaluated the performance of resin composites with different inorganic particle sizes in order to verify whether this factor would result in a greater or lesser stability of the material with regard to surface hardness over time.
The equipment used in this study promoted degradation of the resins by the pre-fixed cycle of the device that uses ultraviolet light, humidity and heat ${ }^{12}$.

This study demonstrated significant difference between the resin brands with regard to hardness, therefore a comparative data analysis was performed among the resins, in which it was observed that some groups presented a similar behavior before and after accelerated artificial aging: Herculite (microhybrid $-60 \%$ by vol $-0.6 \mu \mathrm{m}$ ) and Tetric Ceram (microhybrid $-60 \%$ by vol $-0.7 \mu \mathrm{m}$ ); P60 (condensable- $61 \%$ by vol -0.01 to $3.5 \mu \mathrm{m}$ ) and $\mathrm{Z} 250$ microhybrid $-60 \%$ by vol -0.01 to $3.5 \mu \mathrm{m}$ ); Charisma (microhybrid $-60 \%$ by vol $-0.02-2 \mu \mathrm{m}$ ). Seasons (ni 0.04 to $3 \mu \mathrm{m}$ ). Tetric (microhybrid $-60 \%$ by vol $-0.7 \mu \mathrm{m}$ ); Seasons ni -0.04 to $3 \mu \mathrm{m}$ ) and Herculite (microhybrid $60 \%$ by vol $-0.6 \mu \mathrm{m}$ ); Herculite (microhybrid $-60 \%$ by vol $-0.6 \mu \mathrm{m}$ ) and Supreme (nanoparticulate $-59.5 \%$ by vol -5 to $20 \mathrm{~nm}$ ).

The results suggest that AAA did not affect the surface hardness of the composites studied. However, the resin Z100 (microhybrid $-71 \%$ by vol $-0.6 \mu \mathrm{m}$ ) can be considered the ideal material as it presented greater hardness when compared to the others, both before and after AAA, suggesting that according to the composition table indicated by the manufacturers, materials with higher silica/Zirconia have better surface hardness.

The area-volume ratio of the composite particles is more favorable to the mechanical properties when they have smaller-sized particles, and consequently a greater 
percentage by volume, which results in a better distribution, since the distance between neighboring particles becomes smaller, thereby increasing the contact area ${ }^{29,30}$.

This condition justifies the results of this study where the resin laden with the greatest volume of zirconia and silica showed better performance regarding surface hardness when compared to the others. Although the results are only numerical, the resin groups showed an increase in hardness after aging and the others showed a decrease in hardness, and in all groups where this factor was evaluated, a similarity was observed in their composition, particle size and shape.

Several studies have shown that hybrid composites present a higher degree of surface hardness and of conversion when compared to nanoparticle composites ${ }^{25,27-31}$ and a positive relationship between hardness and inorganic particles. However, Beun et al. ${ }^{2}$, report that nanoparticle composites show mechanical properties similar to those of universal hybrid composites, and can be used for the same clinical applications. In the present study, although the resin with greater load volume $(76 \%)$ presented intermediary surface hardness results when compared to the others, its particles are classified at the nanoscale level.

Studies have demonstrated that water absorption by the matrix and oral temperature conditions may cause failures in these materials, altering the cohesion between the matrix and inorganic particles, consequently reducing their mechanical properties ${ }^{22,7-11}$. The results of our study confirm this assertion since the resins with an organic matrix similarity showed similar mechanical behavior with regards to hardness.

The methodology used showed that in all of the composites evaluated, the effect of aging was not significant to contraindicate their applications. The fact that the microhybrid resin with $71 \%$ loading of silica and zirconia showed better results does not counter indicate, for example, its use in posterior teeth, since it had a superior performance than the composites developed specifically for this purpose, as is the case of packable resin with zirconia/silica $61 \%$ vol. (0.01 to $3.5 \mathrm{~mm})$.

\section{References}

1. American Society for Testing and Materials - ASTM. G15400A: Standard Practice for Operating Fluorescent Light Apparatus for UV Exposure of Nonmetallic Materials. 4th ed. Philadelphia: ASTM; 2006. p. 646-654. Annual Book of ASTM Standards, v. 14.

2. Beun S, Glorieux T, Devaux J,Vreven J and Leloup G. Characterization of nanofilled compared to universal and microfilled composites. Dental Materials. 2007; 23(1):51-59.

3. Braga RR and Ferracane JL. Alternatives in polymerization contraction stress management. Journal of Applied Oral Science. 2004; 12(spe):1-11. http://dx.doi.org/10.1590/S167877572004000500002

4. Brauer EM. Color changes of composites on exposure to various energy sources. Dental Materials. 2008; 4(2)55-9. http://dx.doi.org/10.1016/S0109-5641(88)80090-3
In this study it was observed that although some resins have the same classification in relation to particle size, they show some behavioral differences, suggesting that differences in the properties of composites are related to the current volume by weight, type and distribution of particles to maintain the stability of the materials. The microhybrid composite with the highest volume of silica and zirconia particles showed the highest hardness values.

Another aspect to consider is that although the percentage of load weight given by the manufacturers is similar, the particle type interaction, such as quartz or silica and type of organic matrix, probably influences the mechanical properties of the materials studied. In other words, to conclude the results and for a greater understanding of the mechanical behavior, a characterization analysis of the material is advised, if necessary.

In this study, comparing the composite with the highest surface hardness value to that with the lowest value, both had the same organic matter composition according to the manufacturer's specifications, which in this case attributes the responsibility for the increase in surface hardness to the filler load, in volume and distribution.

Thus, as the surface hardness increase is due to the inorganic composition of the different brands of composites studied and as there is no influence of accelerated artificial aging on the resin groups before and after aging, it can be concluded that all composites are chemically stable and can be indicated for dental restoration, provided they comply with the manufacturer's technical principles and guidelines.

\section{Conclusion}

It was concluded that:

- Accelerated artificial aging did not influence the hardness of any of the resin composites. However with regard to hardness, there was a significant difference between the resin brands.

- All the brands have elements in their composition that maintained their formulation stable, even when submitted to this aging system, since they presented no changes with regard to surface hardness.

5. Cardoso PC, Araújo A, Lopes GC, Araujo E and Baratieri LN. Efeito da refrigeração na rugosidade superficial e dureza das resinas compostas durante o procedimento de polimento. Revista Dental Press de Estética. 2006; 3(1):20-26.

6. Cerveira GP, Berthold TB, Souto AA, Spohr AM and Marchioro EM. Degree of conversion and hardness of an orthodontic resin. European Journal of Orthodontics. 2009; 1-4.

7. Chadwick RG, McGabe JF, Walls AGW and Storer R. The effect of storage media upon the surface micro hardness and abrasion resistance of three composites. Dental Materials. 1990; 6:123-8. http://dx.doi.org/10.1016/S0109-5641(05)80042-9

8. Chinelatti MA, Chimello DT, Ramos RP and Palma-Dibb RG. Evaluation of the surface hardness of composite resins before and after polishing at different times. Journal of Applied Oral Science. 2006;14(3):188-92. PMid:19089071. http://dx.doi. org/10.1590/S1678-77572006000300008 
9. Cruvinel DR, Garcia LFR, Casemiro LA, Pardini LC and Piresde-Souzaa FCP. Evaluation of Radiopacity and Microhardness of Composites Submitted to Artificial Aging. Materials Research. 2007; 10(3):325-329. http://dx.doi.org/10.1590/ S1516-14392007000300021

10. Ferracane JL. Correlation between hardness and degree ofconversion during the setting reaction of unfilled dentalrestorative resins. Dental Materials. 1985;1(1):11-14. http://dx.doi.org/10.1016/S0109-5641(85)80058-0

11. Ferracane JL, Berge HX and Condon JR. In vitro aging of dental composites in water - effect of degree conversion, filler volume,and filler-matrix coupling. Journal of Biomedical Materials Research. 1998; 42:465-72. http://dx.doi. org/10.1002/(SICI)1097-4636(19981205)42:3\%3C465::AIDJBM17\%3E3.0.CO;2-F

12. Gomes PN, Dias SC, Moyses MR, Pereira LJ, Negrillo BG and Ribeiro JC. Effect of artificial accelerated aging on Vickers microhardness of composite resins. General Dentistry. 2008; 56(7):695-9. PMid:19014029.

13. Hahnel S, Henrich A, Rosentritt M, Handel G and Bürgers $\mathrm{R}$. Influence of artificial ageing on surface properties and Streptococcus mutans adhesion to dental composite materials. Journal of Materials Science: Materials in Medicine. 2010; 21:823-833. PMid:19830528. http://dx.doi. org/10.1007/s10856-009-3894-y

14. Kim KH, Ong JL and Okuno O. The effect of filler loading and morphology on the mechanical properties of contemporary composites. The Journal of Prosthetic Dentistry. 2002; 87(6):642-49. PMid:12131887. http://dx.doi. org/10.1067/mpr.2002.125179

15. Koin PJ, Kilislioglu A, Zhou M, Drummond JL and Hanley L. Analysis of degradation of a model dental composite. Journal of Dental Research. 2008;87(7):6615. PMid:18573987. PMCid:2577376. http://dx.doi. org/10.1177/154405910808700712

16. Kournetas N. Impact of artificial ageing process on the wear resistance of dental materials. [Tese]. Tübingen; 2005.

17. Mayworm CD, Camargo Junior SS and Bastian FL. Influence of artificial saliva on abrasive wear and microhardness of dental composites filled with nanoparticles. Journal of Dentistry. 2008; 36(9):703-10. PMid:18554772. http://dx.doi. org/10.1016/j.jdent.2008.05.001

18. Meyer GR, Ernst CP and Willershausen B. Decrease in power output of new light-emitting diode (LED) curing devices with increasing distance to flling surface. Journal of Adhesive Dentistry. 2002; 4(3):197-204. PMid:12666755.

19. Mohsen NM and Craig RG. Hydrolytic stability of silanated zirconia-silica-urethane dimethacrylate composites. Journal of Oral Rehabilitation. 1995; 22:213-20. PMid:7769516. http:// dx.doi.org/10.1111/j.1365-2842.1995.tb01566.x
20. Nicoluzzi A, Moyses MR, Reis AC, Ribeiro JCR and Dias SC. Influencia del envejecimiento artificial acelerado sobre la resistência a compresión de resinas compuestas. Acta Venezolana. 2008; 46(4):1-5.

21. Pereira RA, Araujo PA, Castaneda-Espinosa JC and Mondelli RFL. Comparative analysis of the shrinkage stress of composite resins. Journal of Applied Oral Science. 2008;16(1):30-4.

22. Pereira SMB, Castilho AA, Salazar-Marocho SM, Oliveira KMC, Váquez VZC and Bottino MA. Thermocycling effect on microhardness of laboratory composite resins. Brazilian Journal Of Oral Sciences. 2007; 6(22):1372-1375.

23. Reis AC, Panzeri H and Agnelli JAM. Caracterização microestrutural de uma resina composta condensável condensada manual e mecanicamente. Brazilian Oral Research. 2000; 14:122.

24. Rode KM, Freitas PM, Lioret PR, Powell LG and Turbino ML. Micro-hardness evaluation of a micro-hybrid composite resin light cured with halogen light, light-emitting diode and argonion laser. Lasers in Medical Science. 2009; 24:87-92. PMid:18058187. http://dx.doi.org/10.1007/s10103-007-0527-x

25. Silva EM, Poskus LT and Guimarães JG. Influence of lightpolymerization modes on the degree of conversion and mechanical properties of resin composites: a comparative analysis between a hybrid and a nanofilled composite. Operative Dentistry. 2008; 33(3):287-93. PMid:18505219. http://dx.doi.org/10.2341/07-81

26. Stein PS, Sullivan J, Haubenreich JE and Osborne PB. Composite resin in medicine and dentistry. Journal of LongTerm Effects of Medical Implants. 2005; 15(6):641-654. PMid:16393132.

27. Thomé T, Steagall Junior W,Tachibana A, Braga SRM and Turbino ML. Influence of the distance of the curing light source and composite shade on hardness of two composites. Journal of Applied Oral Science. 2007; 15(6):486-91. http://dx.doi. org/10.1590/S1678-77572007000600006

28. Tsui TY and Joo Y. A new technique to measure through film thickness fracture toughness. Thin Solid Films. 2001; 401(12):203-10. http://dx.doi.org/10.1016/S0040-6090(01)01613-3

29. Turssi CP, Ferracane JL and Vogel K. Filler features and their effects on wear and degree of conversion of particulate dental resin composites. Biomaterials. 2005; 26:49324937. PMid:15769527. http://dx.doi.org/10.1016/j. biomaterials.2005.01.026

30. Xing XS and Li RKY. Wear behavior of epoxy matrix composites filled with uniform sized sub-micron spherical silica particles. Wear. 2004;256:21-6. http://dx.doi.org/10.1016/ S0043-1648(03)00220-5

31. Yanikoglu N, Duymus ZY and Yilmaz B. Effects of different solutions on the surface hardness of composite resin Materials. Dental Materials Journal. 2009; 28(3): 344-351. PMid:19662734. http://dx.doi.org/10.4012/dmj.28.344 